\title{
Continuous Flow Liquid-Liquid Separation Using a Computer-Vision Control System: the Bromination of Enaminones with $\mathbf{N}$ - Bromosuccinimide
}

\author{
Matthew O'Brien*a \\ Dennis Cooper ${ }^{\mathrm{a}}$ \\ a Lennard-Jones Building, School of Physical and Geographical \\ Sciences, Keele University, Keele, Borough of Newcastle- \\ under-Lyme, Staffordshire, UK, ST5 5BG. \\ m.obrien@keele.ac.uk \\ Dedicated to Professor Steven V. Ley, mentor and \\ friend, on the occasion of his $70^{\text {th }}$ Birthday.

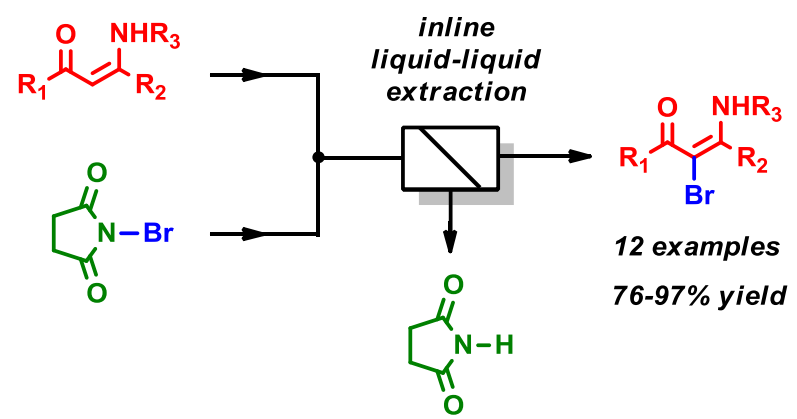

Abstract Incorporating open-source software components (Python, OpenCV), a computer-vision system was used to control the interface level in a gravitybased inline liquid-liquid separation device. This was used in the continuous flow bromination of a series of enaminone substrates. The main byproduct of the reaction, succinimide, was efficiently extracted into the aqueous stream, providing clean products without the need for further purification.

Key words Continous-flow. Liquid-liquid-separation. Bromination. Enaminone. Open-source. Computer-vision. OpenCV. Python.

In recent years, flow-chemistry has emerged as an attractive alternative to traditional batch protocols for chemical synthesis. ${ }^{1}$ Although batch chemistry is perfectly suitable for many synthesis processes, flow-chemistry often offers significant advantages. As reactants and reagents are continuously pumped through a relatively small reaction zone, only a small quantity of material is being processed at any one time. Reactions are then scaled over time (or through parallelisation) rather than by increasing dimension. This provides an enhanced safety profile and is particularly important for reactions that involve the build-up of hazardous, unstable or explosive intermediates, or that use hazardous conditions (e.g. high temperatures or pressures). ${ }^{2}$ Another related issue is the scale-variant nature of several important reaction parameters (e.g. surface-area to volume ratio). These can play a crucial role in the outcome of a reaction as they determine the rate of heat, light and material transfer across interfacial boundaries. ${ }^{3}$ As a result, for many batch process, scaling up can often involve significant re-optimisation. As the reaction/contact zones of a flow-chemistry system are essentially fixed, this leads to efficient, scale-invariant processes that need only be optimised once. ${ }^{4}$ Whilst reaction processes themselves are clearly important to any chemical transformation, the overall synthesis operation can involve many other post-reaction processes (including workup, isolation and purification). The development of flow chemistry 'equivalents' to these batch protocols is clearly an important area of research and currently enjoys significant activity. This is particularly important in the context of truly continuous flow multi-step processes, where the byproducts from one process must be removed before the flow stream enters a downstream reaction zone, where they may be incompatible with the intended chemical transformation. In terms of workup and isolation, the incorporation into flow chemistry systems of cartridges of solid-supported reagents for in-line 'scavenging', 'catch-and-release' or 'phase-switching' has been a hugely successful tactic. ${ }^{5}$ This technique is particularly suitable for small-scale reactions. On larger scales, however, the need to use greater quantities of solid-supported reagent leads to issues of cost, and also to problems of material dispersion. ${ }^{6}$

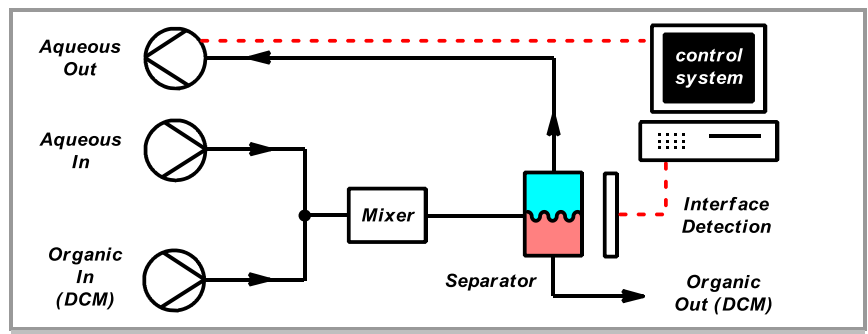

Figure $1 \mathrm{General} \mathrm{schematic} \mathrm{for} \mathrm{a} \mathrm{gravity-based} \mathrm{inline} \mathrm{liquid-liquid} \mathrm{separator.}$

In batch-chemistry, gravity-based liquid-liquid extraction is one of the most commonly used workup/purification protocols, often providing significant purification using very inexpensive reagents and apparatus. The incorporation of inline liquid-liquid extraction into continuous flow chemical systems can provide a 
cost-effective purification stage which does not suffer from depletion (as it is continually replenished) and potentially has scale-invariant dispersion properties. There are two general strategies for achieving this. The selective wetting of materials (such as expanded, porous PTFE) leads to membranes which are essentially impermeable to aqueous solutions but highly permeable to immiscible organic solvents and solutions. This effect has been used successfully in a number of devices and systems. $^{7}$ Alternatively, we have been interested in the development of continuous flow gravity-based separations (see Figure 1 for a general schematic). In general, the organic flow stream is mixed in with an aqueous 'quench/extraction' stream. After mixing, the combined stream enters a separation chamber where the dense phase leaves through the bottom and the light phase leaves through the top. As variation in material transfer between the phases will lead to variation in their relative rate of accumulation in the separation chamber, dynamic positional control of the liquid-liquid interface (which must remain within the separation chamber) is vital. To achieve this, we developed a computer-vision ${ }^{8}$ video system which monitors the position of a coloured 'float' that sits at the liquid-liquid interface (having a density between that of the two phases). ${ }^{9}$ This positional information is then fed-back to control the speed of the pump which extracts the aqueous phase. A similar system has recently been used by the Ley group as part of a multistep continuous flow synthetic sequence. ${ }^{10}$ An alternative approach to interface detection using impedance has also been used in continuous flow systems. ${ }^{11}$

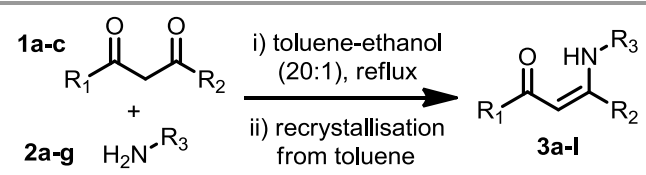

Scheme 1 Condensation reaction between diketones $1 \mathrm{a}-\mathrm{c}$ and amines $2 \mathrm{a}-\mathrm{g}$ to form enaminones $3 a-1$.

Here we report the use of this system in the continuous flow bromination of a series enaminones using $\mathrm{N}$-bromosuccinimide (NBS) as the halogenating agent. ${ }^{12}$ The major byproduct from the reaction, succinimide, can be extracted using aqueous alkali solution. The enaminone substrates $\mathbf{3 a - 1}$ were synthesised using a straightforward condensation reaction between the symmetrical diketones dimedone $\mathbf{1 a}$, cyclohexane-dione $\mathbf{1 b}$ or pentane-2,4-dione 1c, and a series of amines 2a-g (Scheme 1, Figure 2). ${ }^{9}$ Following reflux in a toluene-ethanol mixture, all but one of the enaminone products formed solid products which were easily purified by recrystallisation from toluene. Compound 31 required the excess amine to be removed by aqueous extraction (saturated ammonium chloride) prior to recrystallisation. The yields were moderate to very high and the products were obtained in high purity (by NMR analysis). The flow-chemical apparatus setup used for the bromination reactions is shown in Figure 3. The starting material and NBS were introduced into separate flow streams via injection loops. Dichloromethane was used as the organic solvent for all reactions. The volume of the NBS loop used was longer than that of the starting material. This was to allow for a slight 'overlap' in the 'pulses' which met at the t-junction, ensuring that the starting material would always be accompanied by NBS during each run. After the t-junction, a residence loop controlled (along with the flow rate) the amount of time that the mixture had to react. All reactions were carried out at room temperature.<smiles>CC1(C)CC(=O)C=C(NCc2ccccc2)C1</smiles><smiles>CC1(C)CC(=O)C=C(NC2CCCCC2)C1</smiles><smiles>CC1(C)CC(=O)C=C(NCc2ccc(Cl)cc2)C1</smiles><smiles>CC1(C)CC(=O)C=C(NCc2ccco2)C1</smiles><smiles>O=C1C=C(NCc2ccc(Cl)cc2)CCC1</smiles>

3k $50 \%$<smiles>CC(=O)/C=C(\C)NCc1ccc(Cl)cc1</smiles><smiles>CC1(C)CC(=O)C=C(NCc2ccccn2)C1</smiles><smiles>CCC(C)NC1=CC(=O)CC(C)(C)C1</smiles><smiles>CC1(C)CC(=O)C=C(NCc2ccccc2Br)C1</smiles><smiles>O=C1C=C(NC2CCCCC2)CCC1</smiles>

3h $91 \%$<smiles>O=C1C=C(NCc2ccccc2)CCC1</smiles><smiles>CC(=O)C=C(C)NCc1ccccc1</smiles>

31 $89 \%$
Figure 2 Enaminones formed using the condensation reaction shown in Scheme 1.

Following reaction, a second t-junction allowed the introduction of an aqueous reagent stream. An active mixer (several small PTFE coated stirrer bars in a glass column over a magnetic stirrer) then facilitated rapid mixing of the two phases, before settling and entry into the separation vessel (made from the barrel of a $5 \mathrm{~mL}$ disposable syringe). A webcam pointed horizontally at the separation chamber was used to feed a video stream to the control computer. This used a Python script, incorporating the OpenCV library, ${ }^{13}$ which permitted 'observation' of the vertical position of the interfacial float (see supporting info file for details of all scripts used). ${ }^{14}$ For this work, we found that a float made by fusing a mixture of $210 \mathrm{mg}$ cut from the green plunger of a Norm-Ject $1 \mathrm{~mL}$ PP/PE disposable syringe (which is less dense than water) and $67 \mathrm{mg}$ cut from a green Keck clip (which is denser than dichloromethane) was able to maintain its position at the liquidliquid interface under all conditions used. The two pieces of plastic were fused by holding them together with a pair of tweezers and heating with a heat-gun until they melted. The colour that the computer 'looks for' could be selected by the user at the start of each run (by selecting an object on the 
screen). The script essentially filters the images it receives based on the hue value (HSV image encoding) of the selected colour (within certain tolerances). Some simple processing (involving dilation and erosion) removes 'noise' and the position of the centroid of the largest object with matching hue is determined. The control computer was interfaced to the 'aqueous out' pump. As the pump has a maximum speed (in this case $9.9 \mathrm{ml} / \mathrm{min}$ ) and cannot pump backwards, a true 'proportional' response to positional error is not appropriate. The algorithm used generated a pumping speed of $(2 c)^{3.32}$ $\mathrm{mL} / \mathrm{min}$, where $c$ is the fractional distance along the line between the upper and lower bounds. This way, the speed would be zero when the float was at (or above) the upper bound, $1.0 \mathrm{~mL} / \mathrm{min}$ when the float was halfway between the upper and lower bounds, and at maximum speed $(9.9 \mathrm{~mL} / \mathrm{min})$ when the float was at (or below) the lower bound. Although it would be possible to scale the response curve for different rates of the 'aqueous in' pump, we found that this simple setup provided a robust automated system which adequately maintained the position of the float within the desired bounds, using a wide range of 'aqueous in' flow rates.

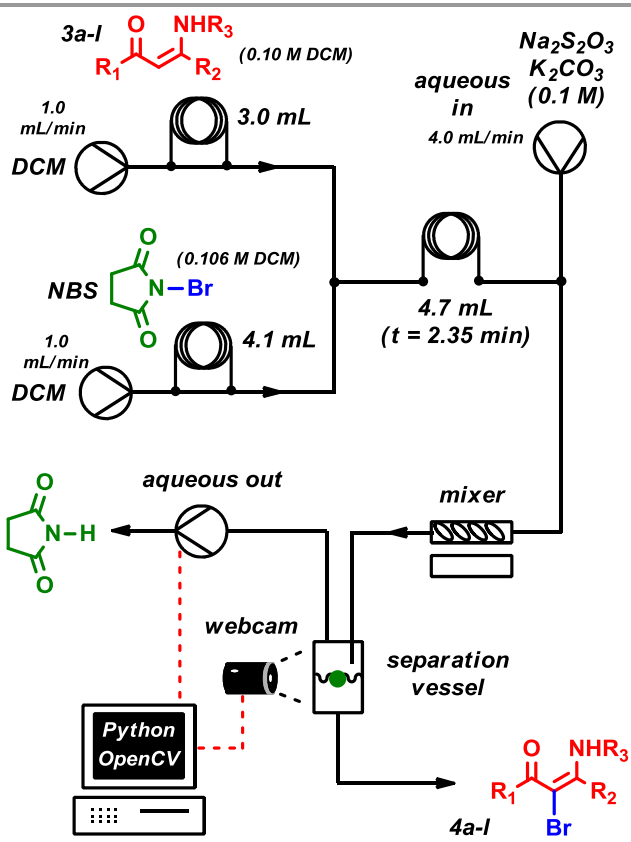

Figure 3 Apparatus schematic for the continuous flow bromination of enaminones $3 a-1$

The control script allows the user to manually select the upper and lower bounds (from a single video frame) at the start of operation. For all the reactions described below, approximately the same upper and lower bounds were chosen for each run and were around $1 \mathrm{~mL}$ apart, with the lower bound around $2 \mathrm{~mL}$ above the bottom of the vessel. Following a brief survey of conditions, using $\mathbf{3 a}$ as our initial test substrate, we found that concentrations of $0.10 \mathrm{M}$ and $0.106 \mathrm{M}$, for the starting material and NBS respectively, with flow rates of $1.0 \mathrm{~mL} / \mathrm{min}$ each and a residence loop of $4.7 \mathrm{~mL}$ ( $2 \mathrm{~min} 21 \mathrm{~s}$ reaction time) led to complete conversion of starting material to product. The NBS reagent loop $(4.1 \mathrm{~mL})$ was 'injected' into the flow stream 20 seconds before the starting material loop $(3.0 \mathrm{~mL})$, providing an overlap of 20 seconds at the start and 46 seconds at the end of the run. For the aqueous extraction, the use of a $0.1 \mathrm{M}$ solution (in each) of sodium thiosulfate and potassium carbonate, injected at a flow rate of $4.0 \mathrm{~mL} / \mathrm{min}$ cleanly extracted all of the succinimide byproduct. With these conditions, the yield of $\mathbf{4 a}$ was almost quantitative. Pleasingly, the yields for the continuous flow bromination of a series of substrates, using the same conditions, were in general very high (Figure 4). Products were obtained in high purity after removal of solvent on a rotary evaporator. Shown in Figure 5 are relevant sections of the NMR spectra for compound $\mathbf{4 f}$ produced with (red spectrum) and without (black spectrum) the aqueous extraction step.<smiles>CC1(C)CC(=O)C(Br)=C(NCc2ccccc2)C1</smiles><smiles>CC(C)(C)O[Mg]</smiles><smiles>CC1(C)CC(=O)C(Br)=C(NC2CCCCC2)C1</smiles><smiles>CCC(C)NC1=C(Br)C(=O)CC(C)(C)C1</smiles><smiles>CC1(C)CC(=O)C(Br)=C(NCc2ccc(Cl)cc2)C1</smiles><smiles>CC1(C)CC(=O)C(Br)=C(NCc2ccccc2Br)C1</smiles><smiles>CC(C)(C)[C@@H]1CC(=O)C(Br)=C(NCc2ccco2)C1</smiles><smiles>O=C1CCCC(NC2CCCCC2)=C1Br</smiles><smiles>O=C1CCCC(NCc2ccc(Cl)cc2)=C1Br</smiles><smiles>O=C1CCCC(NCc2ccccc2)=C1Br</smiles>

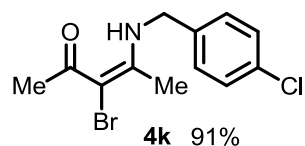<smiles>CC(=O)/C(Br)=C(\[18O])NCc1ccccc1</smiles>

Figure 4 Products $4 \mathrm{a}-\mathrm{l}$ and isolated yields for the continuous flow bromination of enaminones 3a-I. All products were analytically pure (by NMR spectroscopy).

As can be seen, no succinimide can be observed in the extracted sample. Clearly, some dispersion will take place in the heavy phase of the separation vessel. To avoid any loss of material, or cross contamination between runs, we collected the output from each reaction for 20 minutes. As several of the product solutions had a significant yellow colouration, this provided a useful visual indication/confirmation of the time distribution of product concentration in the separation vessel. Shown in Figure 6 are images from screengrabs at various times during the continuous flow synthesis of $\mathbf{4 d}$. The processed images (ii) show (in white) what the computer identifies as having the 'correct' hue, as selected by the user. The centroid of the identified float 
is shown as a small white square in (i), and the upper and lower bounds are shown as small blue circles. As can be seen, despite significant colouration that builds up during the run, as well as some cloudiness in the upper (aqueous) phase, the computervision system is able to distinguish and keep track of the green float during the entire run (the size of the float is magnified by the cylindrical vessel, making it appear larger in these images than it actually is).

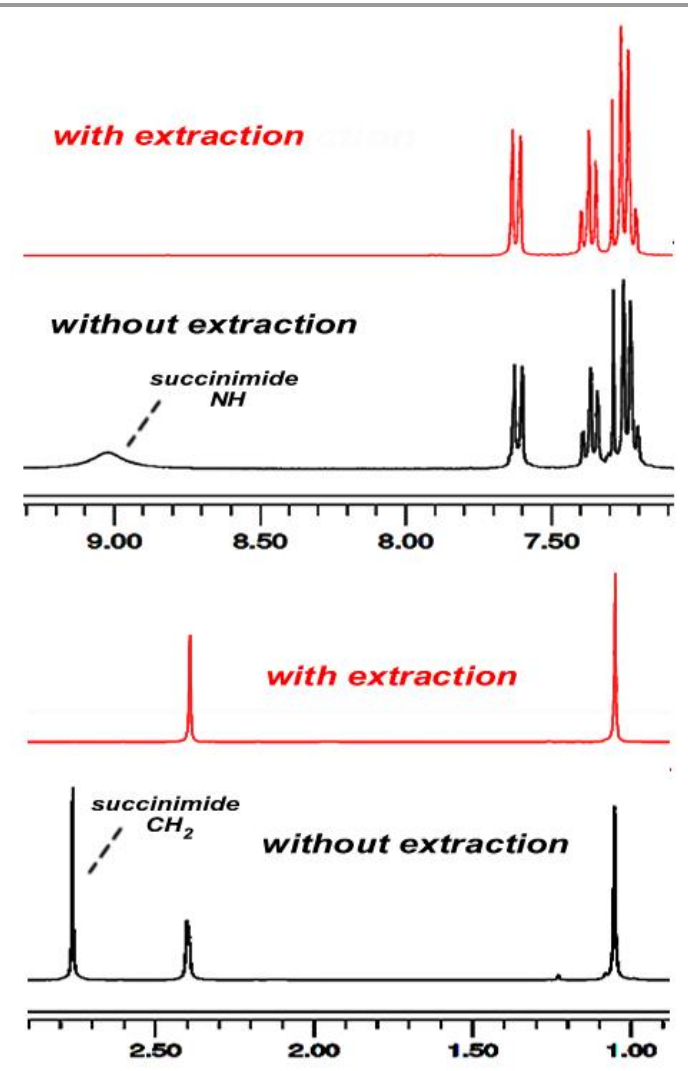

Figure $5{ }^{1} \mathrm{H}$ NMR of the reaction product for the continuous flow bromination of $3 f$ with (red) and without (black) aqueous extraction.

As the float still appears to be the only 'green' object in the image, the system is able operate properly with significant colouration using suitable tolerance parameters. Clearly, if the colouration became strong, or if the solutions are themselves the same colour as the float, then the system might not be able to properly locate the float. It is noteworthy that no observable chemical cross contamination was observed (by NMR spectroscopy) during these reactions, even though the system was never dismantled throughout the entire study. Several consecutive runs were carried out in each laboratory session. At the start of each set of runs, the system was 'primed' for a few minutes by running dichloromethane and aqueous solution through to remove any 'air' from the system/pumps (caused by evaporation of the volatile dichloromethane on standing). At the end of each day, the 'aqueous-out' pump had distilled water pumped through it to avoid any possible settling/build-up of particulates and to prevent possible corrosion. In conclusion, we have successfully used an inline liquid-liquid extraction system, incorporating a computer-vision control system, for the continuous flow bromination of a series of enaminones. ${ }^{15}$ The reactions all proceeded with high chemical yield and, importantly, the extraction system completely removed the succinimide byproduct to afford analytically pure products. We are currently incorporating this system into several multi-step flow syntheses. Additionally, we are quantitatively investigating the dynamic performance of the system under a range of chemical and physical conditions and will report our findings in due course.

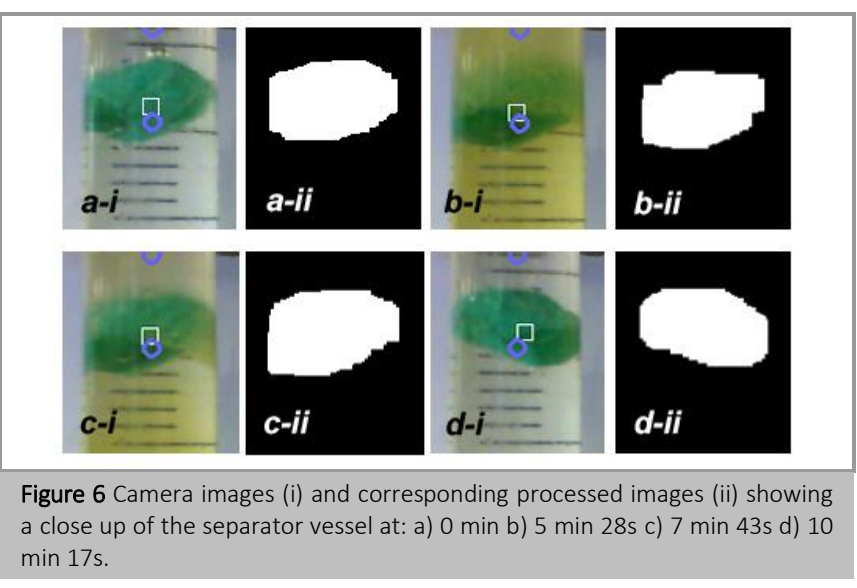

\section{Acknowledgment}

We would like to thank the Keele University Acorn Fund for funding.

\section{Supporting Information}

YES (this text will be updated with links prior to publication)

\section{Primary Data}

NO (this text will be deleted prior to publication)

\section{References and Notes}

1. (a) Pastre, J. C.; Browne, D. L.; Ley, S. V. Chem. Soc. Rev. 2013, 42, (23), 8849. (b) Wegner, J.; Ceylan, S.; Kirschning, A. Adv. Synth. Catal. 2012, 354, (1), 17. (c) Brzozowski, M.; O'Brien, M.; Ley, S. V.; Polyzos, A. Acc. Chem. Res. 2015, 48, (2), 349. (d) Gutmann, B.; Cantillo, D.; Kappe, C. O. Angew. Chem. Int. Ed. 2015, 54, (23), 6688. (e) Pathak, S.; Kundu, A.; Pramanik, A. RSC Adv. 2014, 4, (20), 10180. (f) Ley, S. V. Chem. Rec. 2012, 12, (4), 378. (g) Webb, D.; Jamison, T. F. Chem. Sci. 2010, 1, (6), 675. (h) McQuade, D. T.; Seeberger, P. H. J. Org. Chem. 2013, 78, (13), 6384. (i) Wiles, C.; Watts, P. Chem. Commun. 2011, 47, (23), 6512. (j) Newman, S. G.; Jensen, K. F. Green Chem. 2013, 15, (6), 1456. (k) Yoshida, J. I. Chem. Rec. 2010, 10, (5), 332. (l) Knowles, J. P.; Elliott, L. D.; Booker-Milburn, K. I. Beilstein J. Org. Chem. 2012, 8, 2025. (m) Ley, S. V.; Fitzpatrick, D. E.; Ingham, R. J.; Myers, R. M. Angew. Chem. Int. Ed. 2015, 54, (11), 3449.

2. (a) Brandt, J. C.; Wirth, T. Beilstein J. Org. Chem. 2009, 5, 30. (b) Muller, S. T. R.; Wirth, T. ChemSusChem 2015, 8, (2), 245. (c) O'Brien, M.; Baxendale, I. R.; Ley, S. V. Org. Lett. 2010, 12, (7), 1596. (d) Mastronardi, F.; Gutmann, B.; Kappe, C. O. Org. Lett. 2013, 15, (21), 5590. (e) Maurya, R. A.; Park, C. P.; Lee, J. H.; Kim, D. P. Angew. Chem. Int. Ed. 2011, 50, (26), 5952. (f) Malet-Sanz, L.; Madrzak, J.; Ley, S. V.; Baxendale, I. R. Org. Biomol. Chem. 2010, 8, (23), 5324. (g) O'Brien, M.; Taylor, N.; Polyzos, A.; Baxendale, I. R.; Ley, S. V. Chem. Sci. 2011, 2, (7), 1250. (h) Poh, J.-S.; Tran, D. N.; Battilocchio, C.; Hawkins, J. M.; Ley, S. V. Angew. Chem. Int. Ed. 2015, 54, (27), 7920. (i) Razzaq, T.; Kappe, C. O. Chem. Asian. J. 2010, 5, (6), 1274. 
3. (a) Adolf, W. G., "Mass Transfer Effects on Liquid-Phase Chemical Reaction Rates". In Homogeneous Catalysis, ed. Luberoff, B. A.' American Chemical Society, Advances in Chemistry Series: 1974; Vol. 70, Chapter 3, pp 35. (b) Hobbs, C. C.; Onore, M. J.; Vanthof, H. A.; Mesich, F. G.; Drew, E. H. Ind. Eng. Chem. Prod. Res. Dev. 1972, 11, (2) 220. (c) Markos, J.; Pisu, M.; Morbidelli, M. Computers \& Chemical Engineering 1998, 22, (4-5), 627.

4. (a) Jensen, K. F. Chem. Eng. Sci. 2001, 56, (2), 293. (b) Renken, A.; Kiwi-Minsker, L., Microstructured Catalytic Reactors. In Advances in Catalysis, Vol 53, ed.; Gates, B. C.; Knozinger, H.; Jentoft, F. C.; 2010; Vol. 53, pp 47. (c) Mansur, E. A.; Ye, M.; Wang, Y.; Dai, Y. Chinese Journal of Chemical Engineering 2008, 16, (4), 503.

5. (a) Ley, S. V.; Baxendale, I. R.; Bream, R. N.; Jackson, P. S.; Leach, A. G.; Longbottom, D. A.; Nesi, M.; Scott, J. S.; Storer, R. I.; Taylor, S. J. J. Chem. Soc. Perkin Trans. 1 2000, (23), 3815. (b) Alza, E.; RodriguezEscrich, C.; Sayalero, S.; Bastero, A.; Pericas, M. A. Chem.-Eur. J. 2009, 15, (39), 10167. (c) O'Brien, M.; Denton, R.; Ley, S. V. Synthesis 2011 (8), 1157. (d) Polyzos, A.; O'Brien, M.; Petersen, T. P.; Baxendale, I. R.; Ley, S. V. Angew. Chem. Int. Ed. 2011, 50, (5), 1190.

6. Lange, H.; Carter, C. F.; Hopkin, M. D.; Burke, A.; Goode, J. G.; Baxendale, I. R.; Ley, S. V. Chem. Sci. 2011, 2, (4), 765.

7. (a) Kralj, J. G.; Sahoo, H. R.; Jensen, K. F. Lab Chip 2007, 7, (2), 256 (b) Atallah, R. H.; Ruzicka, J.; Christian, G. D. Anal. Chem. 1987, 59, (24), 2909. (c) Castell, O. K.; Allender, C. J.; Barrow, D. A. Lab Chip 2009, 9, (3), 388. (d) Kolehmainen, E.; Turunen, I. Chem. Eng. Process. 2007, 46, (9), 834. (e) Hornung, C. H.; Mackley, M. R.; Baxendale, I. R.; Ley, S. V. Org. Proc. Res. Dev. 2007, 11, (3), 399.

8. Ley, S. V.; Ingham, R. J.; O'Brien, M.; Browne, D. L. Beilstein J. Org. Chem. 2013, 9, 1051.

9. O'Brien, M.; Koos, P.; Browne, D. L.; Ley, S. V. Org. Biomol. Chem. 2012, 10, (35), 7031.

10. Ingham, R. J.; Battilocchio, C.; Fitzpatrick, D. E.; Sliwinski, E.; Hawkins, J. M.; Ley, S. V. Angew. Chem. Int. Ed. 2015, 54, (1), 144.

11. Sprecher, H.; Payán, M.; Weber, M.; Yilmaz, G.; Wille, G. J. Flow Chem. 2012, 2, (1), 20.

12. Jirkovsk.I. Can. J. Chem. 1974, 52, (1), 55.

13. Bradski, G. Dr. Dobbs J. 2000, 25, (11), 120.

14. For an alternative approach that relates the size of a coloured disk to the vertical distance from a camera see: Wang, T. H.; Lu, M. C.; Hsu, C. C.; Chen, C. C.; Tan, J. D. Measurement 2009, 42, (4), 604.

15. Representative procedure for the formation of the enaminones (3i): Cyclohexanedione (1.55 g, $13.8 \mathrm{mmol}, 1$ equiv.) and 4chlorobenzylamine (1.8 mL, $14.8 \mathrm{mmol}, 1.1$ equiv) were added to a flask under nitrogen. To this was added toluene $(50 \mathrm{~mL})$ and ethanol $(2.5 \mathrm{~mL})$ and the mixture was stirred at reflux for three hours. Upon completion the solvent was removed under reduced pressure, forming a yellow-brown solid which was recrystallised from toluene. Product was made up of yellow-brown crystals. Yield: 71\% (2.31 g). ${ }^{\mathbf{1}} \mathbf{H}$-NMR: $\left(\mathrm{CDCl}_{3}, 300 \mathrm{MHz}\right) \delta 7.32-7.26(2 \mathrm{H}, \mathrm{m}), 7.18(\mathrm{~J}=$ $8.54 \mathrm{~Hz}, 2 \mathrm{H}, \mathrm{m}), 5.34(1 \mathrm{H}, \mathrm{s} \mathrm{br}), 5.07(1 \mathrm{H}, \mathrm{s}), 4.18(\mathrm{~J}=5.36 \mathrm{~Hz}, 2 \mathrm{H}, \mathrm{d})$, $2.38(\mathrm{~J}=6.15 \mathrm{~Hz}, 2 \mathrm{H}, \mathrm{t}), 2.27(\mathrm{~J}=6.53 \mathrm{~Hz}, 2 \mathrm{H}, \mathrm{t}), 1.99-1.91(2 \mathrm{H}, \mathrm{m}$, H-2). ${ }^{13}$ C-NMR: $\left(\mathrm{CDCl}_{3}, 100 \mathrm{MHz}\right) \delta 197.4,165.2,135.3,133.6,128.9$, 97.5, 46.3, 36.4, 29.5, 21.9. IR: $\bar{v} 3247$ (N-H), 3049, 1538 (C=0), 683 Melting Point: $166.8-168.4^{\circ} \mathrm{C}$ (Literature value: $170-172{ }^{\circ} \mathrm{C}$ ).

Representative procedure for the continuous flow bromination (4i) Using the apparatus shown in figure 3 , the system was primed with dichloromethane and the aqueous extraction solvent for several minutes until there were no air gaps in the flow path. 3-[(4chlorobenzyl)amino]cyclohex-2-enone $\quad 3 i \quad\left[\begin{array}{llll}0 & M & \text { in }\end{array}\right.$ dichloromethane) was loaded in to the $3 \mathrm{~mL}$ injection loop. $\mathrm{N}$ bromosuccinimide $(0.106 \mathrm{M}$ in dichloromethane) was loaded into the $4.1 \mathrm{~mL}$ injection loop. The NBS loop was injected into the system 20 seconds prior to the substrate loop. Organic solution exiting the system was collected for 20 minutes. The solvent was removed under reduced pressure to afford a yellow-brown solid. Yield: 93\% (87.5 mg). ${ }^{1} \boldsymbol{H}$-NMR: $\left(\mathrm{CDCl}_{3}, 400 \mathrm{MHz}\right) \delta 7.32(\mathrm{~J}=7.43 \mathrm{~Hz}, 2 \mathrm{H}, \mathrm{d})$, $7.18(\mathrm{~J}=7.65 \mathrm{~Hz}, 2 \mathrm{H}, \mathrm{d}), 6.12(1 \mathrm{H}, \mathrm{s} \mathrm{br}), 4.49(\mathrm{~J}=5.17 \mathrm{~Hz}, 2 \mathrm{H}, \mathrm{d})$, $2.51(\mathrm{~J}=6.34 \mathrm{~Hz}, 2 \mathrm{H}, \mathrm{t}), 2.45(\mathrm{~J}=6.03 \mathrm{~Hz}, 2 \mathrm{H}, \mathrm{t}), 1.98-1.84(2 \mathrm{H}, \mathrm{m})$. ${ }^{13}$ C-NMR: $\left(\mathrm{CDCl}_{3}, 100 \mathrm{MHz}\right) \delta 187.8,161.0,136.0,133.7,129.2$, 128.0, 96.6, 46.5, 36.6, 26.7, 20.7. IR: $\bar{v} 3260(\mathrm{~N}-\mathrm{H}), 2988,2955$, 2939, 2901, 2884, 1584 (C=0), 800, 715. Melting Point: 121.5 $122.3^{\circ} \mathrm{C}$. 
